\title{
O fetichismo na ciência e a crise da razão
}

Fábio De Maria e Carlos Henrique Pissardo*

As reflexões de Max Horkheimer e Theodor Adorno sobre a forma assumida pela ciência no modo de produção capitalista permitem iluminar aspectos centrais da atividade científica, tal qual essa vem sendo desenvolvida até os dias de hoje. O que se propõe no presente artigo é uma exposição dessas reflexões com base em uma diferenciação histórica e teórica entre seus dois principais momentos: de um lado, aquele correspondente à década de 1930, e que tem o ensaio "Teoria tradicional e teoria crítica" de Horkheimer por referência, de outro, aquele relativo à década de 1940, e que teve por obras mais representativas Eclipse da razão (de Horkheimer) e Dialética do esclarecimento (de Horkheimer e Adorno). Trata-se, nos dois casos, de relacionar as análises do caráter fetichista da ciência contemporânea com o modo de produção capitalista em suas diferentes figuras históricas, assim como, mais especificamente, de relacionar a ciência com a forma assumida pela ideologia dominante em cada época dessa sociedade. Com isso, chamamos atenção para alguns passos daquelas reflexões que costumam ser negligenciados pelas tendências dominantes da recepção das teses frankfurtianas, a saber: (a) a continuidade de fundo entre as reflexóes feitas nos anos de 1930 e aquelas formuladas, na década seguinte, na Dialética do esclarecimento e em Eclipse da razão; (b) a importância das transformações pelas quais passava o capitalismo no entreguerras, como elemento mediador desses dois momentos teóricos, incluindo-se aí o processo de integração do proletariado e a reconfiguração do

*Universidade de São Paulo, São Paulo, Brasil. 
papel da técnica, alçada a mecanismo de dominação central no âmbito do "mundo administrado"; e (c) o caráter rigorosamente histórico-materialista do processo de subjetivação da razão e de inversão dialética da ciência em magia, processos aos quais se costuma associar a suposta centralidade, na obra escrita por Horkheimer e Adorno a partir da década de 1940, de uma "filosofia pessimista da história".

\section{A forma da ciência sob o modo de produção capitalista}

Mais do que um elenco dos critérios metodológicos suficientes para opor dois tipos diferentes de conhecimento, o ensaio "Teoria tradicional e teoria crítica", publicado por Max Horkheimer em 1937, consiste em uma potente crítica ao caráter fetichista da ciência contemporânea, ela própria uma figura específica do processo mais geral de reificação das relações sociais.

A concepção tradicional de teoria, segundo o autor a compreende, consiste em um conjunto fechado de proposições vinculadas entre si e deduzíveis umas das outras isso de forma pretensamente independente do ambiente natural e histórico em meio ao qual se constitui. $\mathrm{O}$ critério de validade desse conjunto seria, em primeiro lugar, uma hipotética consonância entre as proposições científicas que o sustentam e os fatos observados: "tem-se sempre, de um lado, o saber formulado intelectualmente, e de outro um estado de coisas que deve ser apreendido sob ele, e esse subsumir, esse produzir da relação entre a mera percepção ou constatação do estado de coisas e a estrutura conceitual de nosso saber se chama a sua explicação teórica" (Horkheimer, [1937] 1988b, p. 167). A fim de garantir a coerência entre as proposições - outro requisito da validade das teorias científicas - os fatos constatados são simplificados e, após suas contradições internas serem eliminadas, são integrados em um sistema conceitual, desprezando-se as singularidades dissonantes que possam conflitar com ele. Essa adequação deve resultar na constituição de um sistema não contraditório de proposições apoiadas em um número o menor possível de princípios gerais, capazes de serem empregados na investigação dos domínios mais variados e aplicados aos mais diversos fatos singulares. Ao fazê-lo, a ciência tende ao ideal, conquanto distante, da constituição de um sistema universal capaz de abranger todos os objetos possíveis, pertencentes à natureza viva ou morta, de maneira que nada lhe escape.

Nesse contexto, é irrelevante para Horkheimer a distinção entre as concepções epistemológicas que defendem a primazia da pesquisa teórica e aquelas que defendem a primazia da pesquisa empírica: a teoria tradicional pode tanto seguir as concepções empiristas clássicas e proceder por meio da indução feita com base em casos singulares, conhecidos por meio da observação dos "fatos" e universalizados para a constituição de teorias, quanto consistir, antes, no recurso a teorias gerais e princípios 
estabelecidos de antemão, para então verificar a adequação dos fatos observados às hipóteses que presidiram sua seleção. Em um caso como no outro, trata-se de uma concepção dualista, isto é, não dialética, da relação entre a teoria e o mundo empírico, que não por acaso acaba sempre por se interverter - em um movimento de passagem ao oposto - em uma busca obsessiva por identidades, a serem pretensamente obtidas por um controle crescente de tudo que foge ao sistema. Para a teoria tradicional, portanto, a ideia de verdade equivale à de correspondência entre teoria e realidade empírica, independentemente de onde parta o conhecimento.

Os empiristas lógicos do Círculo de Viena são, para Horkheimer, um caso bastante revelador desse fazer científico. Inspirados no modelo de conhecimento da Física, os empiristas lógicos desprezavam a noção de totalidade histórica e reduziam o conhecimento à verificação empírica de juízos individuais (ou ao estabelecimento de relações lógicas entre juízos que pudessem ser reduzidos, em última análise, a observações diretas). Defendiam, ao mesmo tempo, o emprego da lógica matemática e de seus procedimentos de formalização com o objetivo de eliminar as imprecisões da linguagem científica e de promover a simplificação e a uniformização dos conceitos. Isso permitiria reduzir a distância entre as disciplinas rumo ao ideal de uma ciência unitária que, composta do menor número possível de leis, permitisse a previsão de eventos. A eliminação, do âmbito da ciência, de enunciados sem sentido inequívoco a converteria em um sistema de relações lógicas baseadas em enunciados significativos - esses, na perspectiva dos membros do Círculo de Viena, seriam apenas os enunciados baseados em observações diretas, ou aqueles que pudessem ser postos em relação lógica com enunciados baseados em observações diretas, sendo passíveis, portanto, de "redução aos mais simples enunciados sobre o empiricamente dado" (Neurath et al., 1929, pp. 205-306; ver também Carnap, 1931, p. 236). A construção de uma "ciência unitária" seria possível por meio do trabalho coletivo dos especialistas, submetido ao crivo da linguagem universal da lógica matemática, que superaria as imperfeições das linguagens historicamente surgidas ${ }^{1}$.

1. No caso das ciências sociais e históricas, por exemplo, a eliminação dos conceitos metafísicos e a reunião das contribuições científicas de diversas origens foram imaginadas da seguinte maneira: "não é difícil deixar de fora conceitos como 'espírito do mundo' e, em vez disso, tomar como objetos grupos de indivíduos de determinada espécie. Quesnay, Adam Smith, Ricardo, Comte, Marx, Menger, Walras, Müller-Lyer [...] atuaram com base em uma postura empirista, antimetafísica. O objeto da história e da economia política são os homens, as coisas e sua combinação" (Neurath et al., 1929, p. 313). Um pouco antes se lê: "apresenta-se a nós como objetivo a ciência unitária. Os esforços se dirigem no sentido de vincular e tornar harmônicas entre si as contribuições dos pesquisadores individuais nas mais diversas áreas da ciência. Desse objetivo resulta a ênfase dada ao trabalho coletivo; daí resulta também que ressaltemos aquilo que é apreensível intersubjetivamente; daí a procura de um sistema neutro de fórmulas, de uma linguagem simbólica livre das impurezas das línguas históricas; daí a procura também de um sistema total dos conceitos" (Idem, p. 308). 
Esse conceito tradicional de teoria, tão bem exemplificado no empirismo lógico do Círculo de Viena, revela a um exame crítico seu caráter ideológico. A suposta independência das teorias científicas em relação à sociedade (na qual se encontrariam suas fontes meramente "externas"), a ilusão de que as teorias científicas subsistiriam por si mesmas (da qual decorre a ideologia da liberdade dos cientistas, cuja atividade seria "livre de valores, interesses e paixões"), é apenas um caso específico da ilusão que, na sociedade burguesa, acomete os processos de trabalho em geral: seus produtos são considerados como se não tivessem história e não fossem expressão de relações sociais, antes subsistindo por si mesmos, na forma imediata sob a qual se apresentam à percepção. As teorias científicas são, contudo, segundo Horkheimer, e na própria forma independente e a-histórica sob a qual se apresentam, a expressão reificada do processo social capitalista, e sua conexão com as demais atividades humanas, não sendo transparente, apenas pode ser compreendida por meio da construção das mediações que vinculam ao processo social esse conceito abstrato de "teoria" (Horkheimer, 1988b, pp. 171-173). Nesse sentido, aquela identidade postulada pela teoria tradicional entre sujeito e objeto, isto é, entre a teoria e os fatos, seria ela mesma um produto da realidade social que, não obstante, nunca se realiza totalmente: em uma sociedade fundada na alienação, a relação entre sujeito e objeto é, na verdade, trespassada de mediações, das quais decorrem o caráter pré-formado dos "fatos" - eles próprios codeterminados de antemão por representaçôes, antes mesmo de sua teorização propriamente científica - e o caráter histórico das "teorias" - elas próprias determinadas pelo material empírico, factual (Idem, p. 174) ${ }^{2}$. A redução de toda a realidade a fatos imediatos, a serem fixados em sentenças protocolares e integrados em um sistema lógico, constitui tentativa de apagar a tensão entre sujeito e objeto e qualquer ideia de uma realidade situada para além da experiência sensível imediata daquilo que está dado. Cada vez mais restrita à formalização do existente, sem dar conta de seu próprio caráter mediado, esse tipo de racionalidade se converte no contrário do conhecimento (Horkheimer, [1937] 1988c, p. 129 e pp. 131-132).

Isso porque a redução da ciência a meros atos de observação e de formalização matemática a torna incapaz de se vincular a finalidades racionais que ultrapassem

2. A consciência do caráter histórico da ciência não levava Horkheimer, contudo, à ideia de uma sociologia do conhecimento, muito pelo contrário: a versão dada por Mannheim à teoria da ideologia foi criticada pelo autor, que argumentava ter o conceito marxiano sido, em Ideologia e Utopia, esvaziado de seu caráter negativo original ("consciência invertida da realidade") e subordinado a ideias de fundo metafísico, adquirindo um sentido oposto àquele presente na crítica de Marx e Engels à filosofia da história dos jovens hegelianos. Ver Horkheimer ([1930] 1987a, pp. 271-276 e pp. 280-281). Sobre as críticas de Horkheimer a Lukács e a Mannheim, ver Puzone (2017). 
o pensamento analítico; a teoria tradicional termina por excluir do processo de conhecimento o papel ativo do sujeito. Mesmo o empirismo de Locke e Hume, argumenta Horkheimer, não os havia impedido de elaborar uma teoria do conhecimento e uma reflexão sobre o ser humano em geral. Já no empirismo lógico e nas correntes dominantes da ciência contemporânea, a referência ao sujeito desaparece e a teoria é reduzida a um conjunto fechado de proposições logicamente vinculadas entre si, dadas supostamente sem quaisquer mediações sociais, mas, por isso mesmo, mais cegamente nelas inseridas (Horkheimer, 1988c, p. 118, e também Horkheimer, 1988b, p. 162).

E por quais mediações passa a ciência no modo de produção capitalista? A resposta de Horkheimer é bem conhecida: “[...] da mesma maneira que a influência do material sobre a teoria, também a aplicação da teoria ao material não é apenas um processo intracientífico, mas também, ao mesmo tempo, um processo social. Afinal de contas, a relação entre as hipóteses e os fatos não se realiza na cabeça dos estudiosos, e sim na indústria”. (Horkheimer, 1988b, p. 170)

A teoria tradicional, sendo a mais apta ao domínio da realidade por meio do controle dos objetos de investigação - enquadrados em esquemas teóricos coerentes e de aplicação geral - é, assim, a mais adequada ao funcionamento e reprodução da sociedade burguesa, não por acaso também fundada na dominação da realidade pela forma mercadoria. Para Horkheimer, os cientistas participam da reprodução do existente na medida mesmo em que se julgam independentes e conduzem a sua prática de modo supostamente isolado das demais esferas. A aplicação do método cartesiano a potencialmente todos os objetos da natureza e da sociedade se deve à necessidade do controle o maior possível sobre os fatos e da sua simplificação com vistas à adequação à teoria: esse procedimento - cuja generalização levaria a ciência tendencialmente a se converter em um mero conjunto de sinais lógico-matemáticos - é, desse modo, inseparável do processo de reprodução do capital e da transformação do saber científico em fonte de valor, em uma época na qual a ciência passou a ser aplicada sistematicamente ao processo produtivo. O saber produzido pela teoria tradicional possui, portanto, já em sua origem, uma constituição tal que o torna capaz de gerar valor (sendo um saber "valorizável”, verwertbar). Da mesma maneira que o capital reduz o mundo (inclusive o próprio conhecimento) a valores de troca, que se justapõem abstratamente na realidade sem quaisquer qualidades próprias e sem história ou desenvolvimento ulterior propriamente dito, a ciência que a ele corresponde também pretende reduzir seu objeto a um "sistema de sinais puramente matemáticos" cada vez mais abstrato e livre de "excessos" qualitativos (Horkheimer 1988b, p. 164, pp. 168-171; ver também Horkheimer, [1932] 1988a, pp. 41-42). 
Crise do capitalismo, crise da ciência

A ciência orientada por esse método é, portanto, um momento do desenvolvimento das forças produtivas capitalistas; como essas, ela também está submetida a certa perversão histórica de suas possibilidades emancipatórias. Para Horkheimer, é certo que a teoria tradicional exerceu uma função revolucionária quando da ascensão social da burguesia em sua luta contra o Antigo Regime: ao defender que a ciência deveria ser independente de considerações teológicas, políticas e morais, ela teve seu momento progressista quando desprezou como "extracientíficos" fatores que não proviessem da própria esfera da ciência e circunscreveu a atividade dos cientistas aos fatos observados. Quando, entretanto, esse conceito de teoria pretendeu se autonomizar em relação ao processo social em meio ao qual surgira, desvinculando-se da função histórica original que havia exercido, ele se tornou "uma categoria reificada, ideológica" (Horkheimer, 1988b, p. 168; ver também Horkheimer, 1988a, pp. 42-45). Na fase monopolista do capitalismo, baseada no poder econômico e político de algumas grandes corporações, as expectativas que a ciência cultivara no período liberal se tornam um momento de obstrução do desenvolvimento da sociedade na direção de uma organização mais afim às necessidades humanas (Horkheimer, 1988a, p. 43).É por isso que, da mesma maneira que as demais forças produtivas, também a ciência se encontra em crise:

Os conhecimentos científicos partilham do destino das forças produtivas e dos meios de produção de outros tipos: a medida de sua aplicação está em grave discrepância com seu alto grau de desenvolvimento e com as reais necessidades da humanidade; isso impede também seu futuro desenvolvimento quantitativo e qualitativo. Como demonstra o curso de crises anteriores, o equilíbrio econômico só se restabelecerá após a destruição, em escala considerável, de valores humanos e materiais (Idem, p. 41).

Mais do que um fenômeno cíclico (que, no entanto, não deve ser negado), a crise do capitalismo que interessa a Horkheimer nesse contexto diz respeito à distância inelutável (no capitalismo) e cada vez maior entre o nível de riquezas produzidas e a satisfação das necessidades humanas que o sistema efetivamente proporciona. Horkheimer aprendera com Marx que, ao contrário do que se afirma nas introduçóes dos manuais de Economia liberais, nem sempre o objetivo de um sistema econômico é o de responder às necessidades humanas em uma situação de escassez. Certamente, pelo menos não no capitalismo: ele bem sabia que nele a produção visa apenas à reprodução ampliada de si mesma e não à realização dos interesses dos indivíduos - esta, quando muito, é contemplada apenas indiretamente, não havendo correspondência necessária entre o progresso econômico e o bem-estar humano. 
A ciência tradicional que Horkheimer então critica, orientada pela mera coleta de fatos e pelo estabelecimento de regularidades entre eles, em sua incapacidade para compreender o processo histórico, torna-se absolutamente inapta a pensar criticamente o todo social do qual depende a própria definição das tarefas da ciência - os interesses propriamente humanos estão, por isso, excluídos de seu horizonte. Tal qual ocorre na sociedade burguesa em geral, em que a racionalidade intrínseca à atividade individual convive com a alienação dos indivíduos em relação ao todo social, a esfera específica da ciência contemporânea, ao alçar aquele procedimento formal à condição de método dominante, é atravessada por uma crise que a atinge em seu cerne:

Também na ciência aparece uma dupla contradição. Em primeiro lugar, vale como princípio que cada um de seus passos tenha um fundamento no conhecimento, mas o passo mais importante, isto é, a própria definição de suas tarefas, prescinde da fundamentação teórica e parece estar entregue ao arbítrio. Em segundo lugar, a ciência se ocupa do conhecimento de conexões abrangentes; ela é incapaz, contudo, de compreender em sua vida efetiva a abrangente conexão da qual depende sua própria existência e a direção de seu trabalho, isto é, a sociedade (Horkheimer, 1988a, p. 45).

Note-se que Horkheimer não se referia aqui ao cientista como indivíduo. As intenções deste podem ser as melhores possíveis ao buscar na ciência sua potência produtora de mais bem-estar para a humanidade; ele até pode ter uma relação crítica com os pressupostos éticos que orientam suas pesquisas e as finalidades dessas - da mesma forma como um capitalista individualmente pode visar a algo muito diverso da obsessiva reprodução ampliada do capital como um fim em si mesmo. Não obstante, ao tornar-se momento da reprodução do capital, a ciência se desenvolve de forma independente da intencionalidade dos indivíduos nela implicados, que aparecem então, tendencialmente, apenas sob a forma de portadores de um movimento objetivo que não podem controlar.

Essa contradição básica, que não depende da iniciativa individual e não pode ser superada no âmbito do modo de produção capitalista - núcleo mesmo do que Horkheimer chama de crise da ciência -, faz-se sentir em diversos níveis da prática científica contemporânea, cuja configuração passa a se dar de acordo com uma intrincada injunção de minuciosa racionalidade, de um lado, e mera e arbitrária irracionalidade, de outro. Por isso é possível falar de uma crise interna da ciência: ela não apenas participa do destino geral das forças produtivas sob o capitalismo e está condenada, apesar de seu alto grau de desenvolvimento, a finalidades humanamente irracionais, mas sua própria forma encontra-se radicalmente afetada em razão disso. A ciência contemporânea submete-se a um "aplainamento metódico e conteudís- 
tico" (Hokheimer, 1988a, p. 43), que a condena a uma crescente irracionalidade: partícipes da crise, os conceitos científicos tendem a ser fetichizados, considerados como se não tivessem história e fossem naturais, tornando-se rígidos e conduzindo a insuficiências das mais diversas ordens, visíveis na arbitrariedade da definição dos problemas de investigação (pensemos, por exemplo, nas "agendas de pesquisa" que surgem como resposta a um determinado problema social ou político e se tornam independentes, ganhando vida própria e subsistindo na comunidade científica mesmo quando seu fundamento histórico se esvaiu), no enrijecimento dos sistemas teóricos (pensemos, por exemplo, na adequação muitas vezes forçosa dos fatos às teorias previamente estabelecidas), na incapacidade da ciência dominante de compreender o processo social para além de seus momentos isolados, por constituir-se com base em uma divisão arbitrária entre as disciplinas, ao longo da qual o privilégio de determinados objetos e questóes em detrimento de outros conduz a obscuridades e juízos errôneos - assim, por exemplo, lembrava Horkheimer, aquilo que é objeto de explicação e discussão na física é pressuposto como algo não-problemático na biologia e vice-versa; o mesmo poderia ser dito das relações entre a sociologia e a psicologia (Horkheimer, 1988b, pp. 171-172).

Criadas pelos sujeitos em suas relações sociais, as teorias e conceitos científicos passam a se apresentar como coisas, como se fossem independentes do processo histórico que os originou - e isso no instante mesmo em que o caráter supostamente independente da ciência revela de forma mais radical sua própria historicidade, isto é, o seu pertencimento ao processo de reificação próprio ao capitalismo. A atividade científica se torna um fato entre outros e com eles compartilha o destino comum de ratificar a irracionalidade do presente tal como está dado, característica da atitude passiva na qual os indivíduos se defrontam com a realidade no modo de produção capitalista. Os indivíduos se submetem, então, à autoridade da verdade científica, como coisa em si, da mesma maneira que se submetem à autoridade dos fatos econômicos, das supostamente inescapáveis leis do mercado, e também na ciência as relações sociais assumem, portanto, a "forma fantasmagórica de uma relação entre coisas” (Marx [1867] 1983, p. 71)

3. A crítica feita por Horkheimer em seus ensaios da década de 1930 ao caráter fetichista da ciência, apesar de bastante palpável, nem sempre tem sido ressaltada nos comentários à sua obra, nem mesmo naqueles mais minuciosos. Ver, por exemplo, Abromeit (2011) especialmente o capítulo 8, onde caberia uma discussão a esse respeito. Helmut Dubiel, por sua vez, em seu clássico estudo ressaltou o caráter "abstrato" do conhecimento produzido segundo o método analítico da ciência empirista, mas o associou à especialização crescente das disciplinas, sem considerar a vinculação desse processo com o fenômeno da reificação. Ver Dubiel (1978, pp. 167-169). Essas interpretações tendem a restringir o diagnóstico de "crise da ciência", formulado por Horkheimer no início da década de 1930, à constatação do mau uso das forças produtivas (incluindo a ciência e a tecnologia), cuja desorganização se revela irracional e impede seu emprego para 
Embora Horkheimer se alinhasse, nesse diagnóstico da crise da ciência contemporânea, à tese de Lukács segundo a qual a experiência na sociedade capitalista se reduz à apercepção de fatos que aparecem como unidades isoladas, a sua compreensão da relação do marxismo com a teoria tradicional é fundamentalmente outra. Enquanto o marxista húngaro rejeitava sem mais a ciência burguesa como expressão da alienação à qual os indivíduos estão submetidos no capitalismo, Horkheimer defendia que a teoria tradicional poderia servir à teoria crítica: a adequação entre as hipóteses e os fatos, promovida pela primeira, teria uma validade objetiva e a ela a teoria crítica poderia recorrer. Se os fatos são produtos da práxis social, "por isso tem de haver neles, mesmo que em um sentido limitado, razão" (Horkheimer, 1988b, p. 174). Da mesma forma como as forças produtivas capitalistas devem ser mobilizadas a fim de se superar a crise engendrada por esse sistema, e assim como as ciências naturais hão de guardar a sua validade em uma sociedade que tenha superado a divisão em classes, a teoria crítica pode recorrer, em sua formulação, aos conhecimentos fornecidos pela teoria tradicional: constituídos segundo um modelo de conhecimento que cumpre a função de conservar e reproduzir as relações sociais dadas, esses conhecimentos mudam de função quando integrados a uma exposição do todo histórico orientada pelo futuro, isto é, pela ideia da negação do modo de produção capitalista (Idem, pp. 190, 202 e 214; sobre esse tema, ver também Musse, 1997, p. 70 ss.).

\section{A fase mais recente do capitalismo monopolista}

“Teoria tradicional e teoria crítica”, de 1937, é o ensaio no qual se encontra a versão mais bem acabada da crítica de Horkheimer à ciência tradicional escrita pelo autor na década de 1930. Na década seguinte, ao lado de Adorno, ele irá remeter essas críticas a uma nova e original reflexão sobre as configurações assumidas pela ideologia no capitalismo a eles contemporâneo. Para a compreensão da crítica feita por Horkheimer e Adorno à ciência naquele momento de sua produção teórica mostra-se indispensável o recurso às suas teses sobre as particularidades da fase contemporânea do capitalismo, considerando principalmente as especificidades que caracterizaram o capitalismo monopolista no período do entreguerras ${ }^{4}$.

fins emancipatórios (nessa direção tendem a se desenvolver também as observações de Maurício Chiarello a respeito do assunto, ver Chiarello, 2001, pp. 33-34). Esse elemento, não obstante presente e central, não abarca todo o conteúdo da referida crítica. Exceções a essa tendência de interpretação do pensamento de Horkheimer são, ainda na primeira fase da recepção da obra do autor, o comentário de Wolfgang Bonss e Norbert Schindler (ver Bonss e Schindler, 1982, e, mais recentemente, Genel, 2013).

4. Uma apresentação detalhada das diferentes posições dos membros do Instituto de Pesquisa Social sobre a natureza do capitalismo da época pode ser encontrada em Regatieri (2015). 
As peculiares relações entre economia e política que definem essa época serão pensadas por Horkheimer e Adorno com base em um diálogo com as teses de seu colega Friedrich Pollock e, especialmente, com seu conceito de "capitalismo de Estado". Segundo esse, a concentração crescente de capital havia transformado o mercado em um "pseudomercado", de modo que nessa fase do capitalismo se sobrepunha, às relações mercantis, a atuação do Estado, organizador da produção e da circulação de mercadorias (às quais a atribuição do nome de "mercadorias" torna-se, portanto, passível de questionamento). Disso decorreria, segundo Pollock, a passagem de uma "era econômica” a uma "era política" (Pollock, [1941] 1980, pp. 200-207).

Embora não acatassem sem mais a tese de uma "era política”, para Adorno e Horkheimer era importante ressaltar que, nessa época, a concorrência entre as empresas é transferida para o plano internacional, em que as burguesias monopolistas competem entre si e tomam parte na disputa imperialista e colonialista. Nesse processo, a realização da mais-valia é deslocada para o âmbito do mercado mundial, e o Estado atua como mediador entre a exploração e o ganho dos capitalistas, que não pode mais ser classificado sob a forma de "lucro", pois passa a se assemelhar à "renda": segundo Horkheimer, a mais-valia "é adquirida e distribuída sob o controle estatal - sob o antigo nome de 'lucro' ela continua todavia a correr em grandes quantidades para as mãos dos magnatas da indústria e dos proprietários de terras" (Horkheimer, [1942] 1987b, p. 300). Concomitantemente, ocorre uma profunda modificação na estrutura de classes: a burguesia deixa de ser um conjunto de indivíduos autônomos que celebram e cumprem seus contratos na esfera da circulação e se transforma em uma "clique de dirigentes", um conjunto de diretores de grandes corporações (o mais das vezes, seus acionistas majoritários) agindo em conjunto com os membros da burocracia estatal. Tanto no âmbito interno quanto naquele da concorrência imperialista, os monopólios se unem ao poder estatal e, assim como as burocracias dos sindicatos e partidos de massas, são perpassados por uma estrutura de poder que opõe os líderes (ali, os sindicalistas, aqui a “clique de dirigentes") à massa (Horkheimer, 1985, p. 87). Nesse contexto, a exploração se daria de maneira tendencialmente direta, isto é, o papel mediador exercido pela mercadoria "força de trabalho" seria reduzido e a repressão, a propaganda ideológica e a integração em organizações estatais garantiriam, sob regimes autoritários ou apenas formalmente democráticos, a inocuidade dos sindicatos e a sua reduzida capacidade de negociação ${ }^{5}$. A constituição do "Estado autoritário" coroaria esse desenvolvimento e daria

\footnotetext{
5. É certo que essa situação não significa o fim da sociedade de classes: a exploração do trabalho, ainda que feita de maneira a dispensar o mercado, permanecia estruturante da vida social. A diferença era que, em sociedades nas quais o proletariado havia sido convertido em uma massa de indivíduos, a classe progressivamente deixava de ser fonte de resistência política e ideológica. Horkheimer estava ciente, ademais,
} 
continuidade a um processo de estabilização da dominação e de contrarrevolução que já havia se iniciado anos antes: "a estabilidade do fascismo repousa na aliança contra a revolução e no cancelamento do corretivo econômico [exercido na fase do capitalismo liberal pelo mercado]" (Horkheimer, [1939] 1980, p. 126) ${ }^{6}$.

Esse processo, é certo, não deixou de ter importantes implicações nas próprias relações de trabalho e na forma como a ciência seria a partir de então requisitada pelo capitalismo. Já Pollock, em seu texto de 1941, afirmava que em "todas esferas do Estado a suposição e a improvisação dão lugar aos princípios da administração científica [scientific management]" (Pollock, 1980, p. 206): a racionalização taylorista que os industriais alemães aprenderam de seus colegas fordistas norte-americanos aparece então como protótipo do controle totalitário de todas as esferas da vida social. A ciência, agora imediatamente posta como "administração científica" das coisas e das pessoas, tem sua função social assim atualizada. É verdade que Horkheimer, Adorno e outros membros do Instituto de Pesquisa Social de Frankfurt analisaram o fordismo

de que a transformação da classe trabalhadora em uma massa integrada havia sido preparada durante o período do auge da social-democracia (ver Horkheimer, 1987b, p. 296, e também Horkheimer, 1985, p. 97).

6. Autores como Habermas e Postone sustentaram que a adoção da tese de Pollock do "capitalismo de Estado" por Adorno e Horkheimer, no início dos anos quarenta, teria significado o abandono da crítica do capitalismo em favor de uma crítica da civilização e da técnica, ao que teria se seguido a "filosofia pessimista da história" presente na Dialética do esclarecimento. A leitura que acentua o papel da tese de Pollock nos rumos tomados pela teoria crítica pode ser encontrada, por exemplo, no posfácio escrito por Habermas para uma das edições da Dialética do esclarecimento: Habermas (1986, p. 281). Dessa perspectiva partilharam diversos outros intérpretes (ver Dubiel, 1978, pp. 97-100; Postone, 1993, pp. 84-120; Abromeit, 2011, pp. 410 ss). Entre nós, Marcos Nobre argumentou de maneira semelhante, embora não tenha acolhido todas as conclusões de Habermas e Postone a esse respeito (Nobre, 2008, pp. 45-47). Não obstante terem os ensaios sobre o "Estado autoritário" e sobre "Razão e autoconservação" representado um momento de passagem na obra de Horkheimer (rumo à radicalização da crítica na Dialética do esclarecimento), entendemos que a relação entre as teses de Adorno e Horkheimer e aquelas de Pollock não é compreensível na chave de uma simples "adoção", mas está atravessada por incontornáveis críticas e deslocamentos. Em consonância a isso é possível, a nosso ver, identificar elementos em comum entre a obra escrita na década de 1930 e os textos da década seguinte (o próprio comentário de Marcos Nobre chama a atenção para a existência de linhas de continuidade entre os dois períodos). Nesse sentido, também é preciso considerar que a relação entre as esferas econômica e política recebeu tratamentos diferentes quando se comparam as obras de Horkheimer e Pollock, assumindo nos ensaios do primeiro, como tentamos resumidamente indicar aqui, um caráter dialético e historicizante que é ausente do texto de seu colega. A insuficiência da interpretação dominante, que costuma considerar a adesão sem mais de Horkheimer à tese de Pollock do "capitalismo de Estado" (o que teria supostamente significado um abandono do marxismo, entendido de maneira reducionista pelos intérpretes que partilham dessa leitura), foi captada com muita propriedade por Gustavo Pedroso: “[...] não se trata da simples substituição de uma abstrata determinação econômica por uma igualmente abstrata determinação pela política (2009, p. 170). Discordamos do autor, contudo, quanto à sua tendência a minimizar a incorporação por Horkheimer das teses de Pollock, e a defender a suposta assimilação, pelo diretor do Instituto, da tese de Neumann do "não-Estado". Não é possível, contudo, aprofundar aqui esse assunto. Especificamente sobre as teses de Pollock, ver ainda o comentário de Rugitsky (2008). 
principalmente com base na concentração de capital (em monopólios e oligopólios) e da ampliação de sua circulação (por exemplo, na indústria cultural), e dessa maneira prestaram pouca atenção ao processo de trabalho concreto: pode-se mesmo afirmar que eles de uma maneira geral tomaram como dadas a taylorização dos processos de trabalho e, a partir da segunda metade dos anos de 1930, a integração do proletariado (Demirović, 2002, p. 63). Não obstante, é impossível compreender suas renovadas reflexôes sobre a ciência nos anos $1940 \mathrm{sem}$ a consideração dos processos concretos de reorganização do trabalho e da produção que então se tornavam dominantes. Como afirmava Horkheimer em 1939: "A transformação do premido trabalhador, que no século XIX andava à busca de trabalho, no membro aplicado das organizaçóes fascistas lembra, em seu significado histórico, a transformação, empreendida pela Reforma, do mestre artesão medieval no burguês protestante, ou do pobre aldeão inglês no moderno trabalhador industrial" (Horkheimer, 1980, p. 118).

A racionalização dos processos de trabalho, mediada pela administração científica, estendia-se a diversas esferas da vida social. O fordismo, de uma maneira geral, significou a extensão do caráter de "apêndice da máquina" do trabalhador do chão de fábrica para a sociedade inteira, incluindo-se aí a esfera privada da vida: enquanto, no período do capitalismo liberal, a espontaneidade do trabalhador industrial sofreria limitações principalmente no âmbito da produção, prevalecendo na esfera da circulação a mediação exercida pela mercadoria e a aparente racionalidade da troca, na fase do Estado autoritário, por sua vez, a supressão da espontaneidade do trabalhador se estendia às demais esferas, reduzindo o seu grau anterior de autonomia e transformando a ação política pautada por fins e ideias em mera obediência e adaptação às estruturas burocráticas dos partidos. De apêndice da máquina durante o tempo passado na fábrica, o indivíduo passava a apêndice de um aparato produtivo que se estendia ao consumo, à educação, ao tempo livre e às relações privadas, que então deixavam de ser privadas. Da mesma forma, nesse processo de integração social, diminuía a importância das esferas que haviam até então cumprido a função de mediadoras entre o indivíduo e a sociedade: o mercado e a família ${ }^{7}$.

Nas palavras de Horkheimer, um "véu tecnológico" mais espesso do que aquele encarnado no dinheiro (o qual ainda pressupunha um certo grau de autonomia individual) seria a nova forma de mediação entre os indivíduos: a mediação exercida pela mercadoria teria desaparecido e em seu lugar surgido algo próximo a uma

\footnotetext{
7. A diminuição da importância do papel socializador da família e o declínio da autoridade paterna foram fenômenos aos quais o Instituto de Pesquisa Social de Frankfurt dedicou sua atenção desde o início da década de 1930, como atesta o prefácio escrito por Horkheimer para os "Estudos sobre autoridade e família” (Horkheimer et al., [1936] 1987, p. x). A esse respeito, ver também Horkheimer (1987d, especialmente pp. 378-379).
} 
"imediaticidade", pois o papel mediador da ciência consistiria, no fim das contas, em uma subordinação pouco refletida à autoridade da técnica (Horkheimer, [1942] 1987 c, p. 339 e p. 345).

\section{Ciência e magia}

Essas reflexões sobre o capitalismo monopolista são correlatas a novas formulações sobre a ideologia e a ciência. Em seu esforço por compreender a figura contemporânea assumida pela ideologia, os autores davam prosseguimento, embora com mudanças, à concepção marxiana. De um lado, Horkheimer e Adorno mantinham a compreensão de ideologia como uma abstração que se autonomizou em relação ao todo social do qual se origina: "toda reificação é um esquecimento" (Adorno e Horkheimer, [1947] 1985, p. 215). De outro lado, porém, na fase monopolista do capitalismo o desaparecimento de uma esfera da circulação composta por sujeitos aparentemente autônomos ensejava também mudanças na estrutura e na função da ideologia, que perdia seus elementos de oposição ao existente e de remissão à possibilidade de uma outra ordem social. Ao contrário do que ocorrera no capitalismo liberal, em sua forma contemporânea a ideologia seria uma espécie de prolongamento do existente e teria por função reduplicar uma "realidade compacta e fechada". Exemplo notável dessa concepção se encontra na análise da indústria cultural feita na Dialética do esclarecimento:

\footnotetext{
A indústria cultural derruba a objeção que lhe é feita com a mesma facilidade com que derruba a objeção ao mundo que ela duplica com imparcialidade. [...] A nova ideologia tem por objeto o mundo enquanto tal. Ela recorre ao culto do fato, limitando-se a elevar - graças a uma representação tão precisa quanto possível - a existência ruim ao reino dos fatos. Essa transferência converte a própria existência num sucedâneo do sentido e do direito (Adorno e Horkheimer, [1947] 1985, p. 138) .
}

Aquele "culto do fato", formulado filosoficamente pelo empirismo lógico, mas comum a toda teoria tradicional, passa a ser compreendido agora em uma profundidade até então inédita. Esse "aplainamento" da realidade ao que está posto presentemente, tão próprio à ciência nessa sua versão conservadora, é então interpretado como momento da ideologia contemporânea, que exclui sem mais as contradições que atravessam a sociedade moderna, como aquelas entre sujeito e objeto, teoria e prática, pensamento e vontade. Em comparação com as contradições mantidas no 
pensamento burguês em geral (como na filosofia de Kant ou no liberalismo econômico), esse desenvolvimento contemporâneo do pensamento filosófico-científico é expressão, portanto, de um fetichismo de tipo novo. Como afirmaria Adorno alguns poucos anos mais tarde, "a tradicional crítica transcendente da ideologia é obsoleta. [...] Não há mais ideologia no sentido próprio de falsa consciência, mas somente propaganda a favor do mundo, mediante sua duplicação e a mentira provocadora, que não pretende ser acreditada, mas que pede o silêncio" (Adorno, [1951] 1998, p. 25).

Para compreender essa função atual da ideologia e da ciência, os autores viram-se forçados a refletir sobre a semelhança entre elas e aquilo que aparentemente lhes seria o mais distante, isto é, a magia. Aqui, o argumento se complexifica no sentido de compreender o que agora aparece como um copertencimento entre a ciência a eles contemporânea e um longo processo histórico-civilizacional de racionalização do mundo como dominação, iniciado muito antes do capitalismo (já em práticas mágicas), mas que atinge sua versão mais desenvolvida no capitalismo em sua fase monopolista. A partir de então, a crítica à ciência moderna toma a forma da crítica de uma racionalidade cognitiva que eleva o princípio da identidade e da dominação do não-idêntico a certa necessidade compulsiva da razão.

Em uma passagem bastante conhecida sobre esse empobrecimento da razão que se limita a apenas afirmar o dado, Horkheimer afirma: "quando a ideia de razão foi concebida, pretendia-se alcançar mais do que a mera regulação da relação entre meios e fins: ela era encarada como um instrumento para entender os fins, para determiná-los" (Horkheimer, [1946] 2015, p. 18). De novo, como nos anos de 1930, o que precisa ser compreendido e criticado é essa progressiva incapacidade da razão de determinar para si seus fins últimos, desaparecendo a razão "objetiva”, capaz de se perguntar pela racionalidade da própria realidade, considerada como totalidade objetiva de seres vivos e coisas, indivíduos e instituições, e restando em seu lugar a razão meramente "subjetiva", que reduz o conceito de razão à racionalidade do sujeito e à sua capacidade de adequar meios a fins. Agora, no entanto, os autores irão propor uma crítica a esse empobrecimento da razão por meio da denúncia de uma identidade subterrânea entre o pensamento moderno - no qual se inclui a ciência - e seu suposto antípoda, isto é, o pensamento mágico. Nesses trabalhos, é desnudada em suas entranhas atávicas a divisa da identidade (e da redução da experiência a um "sempre idêntico" que exclui a diversidade), uma divisa tão própria à “administração científica” das coisas que medrou sob o capitalismo monopolista:

Mas quanto mais se desvanece a ilusão mágica, tanto mais inexoravelmente a repetição, sob o título da submissão à lei, prende o homem naquele ciclo que, objetualizado sob a forma da 
lei natural, parecia garanti-lo como um sujeito livre. O princípio da imanência, a explicação de todo acontecimento como repetição, que o esclarecimento defende contra a imaginação mítica, é o princípio do próprio mito (Adorno e Horkheimer, 1985, p. 26).

Por isso, nessas obras a crítica volta-se não apenas contra o positivismo que se crê fundamentado em leis lógicas atemporais, mas também contra toda a tradição do pensamento ocidental: da bíblia cristã à helênica (Homero), passando pela filosofia antiga até o principal nome da filosofia moderna, isto é, Kant. É certo que, muito distante da indiferença positivista pela definição das finalidades humanas, esses pensadores nunca perderam de vista o projeto de estabelecer a validade de ideias capazes de auxiliar o sujeito, como sujeito autônomo, a orientar-se no mundo. Mas, para Horkheimer e Adorno, a superação dos impasses (ou, para usar a terminologia de Horkheimer dos anos de 1930: da crise) da ciência contemporânea passa agora pela crítica dessa longa tradição do pensamento ocidental que, quanto mais pretendeu se afastar do pensamento mágico, mais dependente permaneceu dele. Da magia à hipóstase do conceito, correlata à hipóstase da administração racional do mundo, permanece o impulso ao domínio do não-idêntico, daquilo que não se submete ao sistema. A reificação do sujeito científico contemporâneo que, sem história, sem interesses, sem concretude, volta-se ao mundo apenas como um instrumento de dominação da própria razão, tem raízes históricas muito mais profundas do que os autores acreditavam nos anos de 1930 (Horkheimer, 2015, p. 121).

\section{Considerações finais}

Sobre essa ampliação da análise, é conhecida a interpretação de Habermas. Segundo ela, a partir de obras como a Dialética do esclarecimento e Eclipse da razão, Adorno e Horkheimer se afastariam cada vez mais de uma crítica materialista da sociedade moderna e, especialmente, do marxismo. A rigor, mais do que de um afastamento, Habermas descreve esses trabalhos como uma verdadeira inversão dos pressupostos mais caros também a autores como Georg Lukács e Alfred Sohn-Rethel. Enquanto esses, e o próprio Horkheimer dos anos de 1930, formulariam uma crítica das figuras da consciência remetendo-as às relações de produção capitalistas (e especialmente às relações de troca como um momento dessas relações mais amplas), Adorno e Horkheimer passariam, a partir da década de 1940, a sustentar sua crítica à modernidade, antes, em certa reflexão sobre o "pensamento identificador" - tornando-se o indivíduo capitalista, sempre segundo Habermas, uma mera "forma histórica" desse pensamento. Em suas palavras: 
Lukács havia obtido a forma de objetividade específica da sociedade capitalista partindo de uma análise da relação de trabalho assalariado, relação que se caracteriza pela forma mercadoria da força de trabalho; daí havia deduzido depois as estruturas da consciência reificada tal como esta se expressa no pensamento intelectivo que caracteriza as ciências modernas, sobretudo na autoexplicação filosófica destas por parte de Kant. Horkheimer e Adorno, por sua vez, consideram essas estruturas de consciência, isto é, o que eles chamam de razão subjetiva epensamento identificador, como fundamentais. A abstração que a forma mercadoria implica é meramente a forma histórica na qual o pensamento identificador emprega sua eficácia histórica universal e determina as formas de interação próprias da sociedade capitalista. As referências ocasionais às abstrações reais tornadas objetivas nas relações de troca não nos deve fazer esquecer que Horkheimer e Adorno, diferentemente de Lukács (e de Sohn-Rethel), nunca deduzem a forma de pensamento a partir da forma mercadoria. O pensamento identificador, cujo poder Adorno via de forma mais bem acabada na Filosofia Primeira que na Ciência, tem raízes históricas mais profundas que a racionalidade formal própria da relação de troca; mesmo que seja verdade que apenas em decorrência da diferenciação do valor de troca é que o pensamento identificador adquire uma significação universal (Habermas, 1999, p. 482, grifo nosso).

Segundo Habermas, o que estaria em jogo naqueles textos escritos por Horkheimer e Adorno da década de 1940 seria, portanto, mais do que um simples prolongamento do escopo de análise (já que os autores buscam desde a antiguidade mítica as raízes dessa racionalidade que é criticada): tais obras seriam representativas também de uma verdadeira guinada teórica. Nesse sentido, seria sintomática dessa guinada a substituição do pressuposto radicalmente histórico que estruturava "Teoria tradicional e teoria crítica” por uma espécie de antropologia pessimista que colocaria a autoconservação do sujeito como verdade primeira da história da civilização. Em vez de partir do sujeito radicalmente histórico do capitalismo moderno, Horkheimer e Adorno recorreriam agora a uma espécie de antropologia cujo cerne seria a repressão da vida pulsional, indispensável à civilização - algo muito mais aparentado ao pessimismo do Freud de Mal-estar na civilização do que às ideias de Marx ${ }^{9}$.

Parece-nos, entretanto, que a estratégia habermasiana de leitura é equívoca. Se, em Dialética do esclarecimento e Eclipse da razão, Horkheimer e Adorno perscrutam

9. A interpretação que sustenta a existência, na produção intelectual do Instituto de Pesquisa Social (e na obra de Max Horkheimer em particular), de dois períodos radicalmente distintos (o "materialismo interdisciplinar" do início da década de 1930 e a "filosofia pessimista da história" da década de 1940) se revela frágil na medida mesmo em que um de seus principais pilares (a ocorrência ou não de imbricação entre pesquisas especializadas e reflexão filosófica) é confrontado com a influência que tiveram, sobre a teorização empreendida na Dialética do esclarecimento, as pesquisas sobre antissemitismo e indústria cultural, realizadas nos Estados Unidos no período do exílio. Para uma análise dos aspectos teóricos e institucionais dessa imbricação, ver Klein (2012, pp. 159-186). 
as determinações sociais e psíquicas que engendraram a subjetivação da razão e a conversão da ciência em magia, está claro que esses processos não se desenvolvem abstratamente no âmbito de uma macro-história da razão, mas sim como momentos da vida social. Eles devem ser compreendidos, portanto, na chave daquela interpretação do capitalismo monopolista descrita resumidamente acima. Longe de reduzir-se a uma discussão antropológica ou psicologista (no sentido de "derivar" os rumos tomados pela ciência e pela razão de uma “estrutura da consciência”, antropológica ou psicologicamente dada), o problema se coloca, ainda, com base em uma perspectiva histórico-materialista: o de um diagnóstico materialista do capitalismo a eles contemporâneo e do papel que a ideologia e a ciência nele desempenham. Se a forma conceito, em suas origens, só se deixa compreender em sua proveniência da praça do mercado ${ }^{10}$, a ciência contemporânea tampouco pode ser apreendida sem um diagnóstico do capitalismo, que administra as pessoas e as coisas como os cientistas manipulam suas cobaias em laboratório. Daí permanecer rigorosamente incompreensível essa crítica dos anos de 1940 à razão cognitiva sem sua contraparte na crítica do capitalismo: longe de voltar-se a qualquer ideia de uma estrutura da consciência antropologicamente dada, é da crítica a ela que aqui se trata.

\section{Referências Bibliográficas}

Aвromeit, John. (2011), Max Horkheimer and the foundations of the Frankfurt School. Nova York, Cambridge University Press.

Adorno, Theodor. (1998), "Crítica cultural e sociedade". In: Adorno, Theodor. Prismas: critica cultural e sociedade. São Paulo, Ática, pp. 7-26.

Adorno, Theodor \& Horkheimer, Max. (1985), Dialética do esclarecimento. Rio de Janeiro, Jorge Zahar Editor.

Bonss, Wolfgang \& SCHIndLeR, Norbert. (1982), "Kritische Theorie als interdisziplinärer Materialismus". In: Bonss, Wolfgang \& Honneth, Axel. Sozialforschung als Kritik - zum sozialwissenschaftlichen Potential der kritischen Theorie. Frankfurt am Main, Suhrkamp, pp. 31-66.

CARnAP, Rudolf. (1931), “Überwindung der Metaphysik durch logische Analyse der Sprache”. Erkenntnis, 2: 219-241.

Chiarello, Maurício. (2001), Das lágrimas das coisas: estudo sobre o conceito de natureza em Max Horkheimer. Campinas, Editora da Unicamp.

10. "É essa unidade de coletividade e dominação e não a universalidade social imediata, a solidariedade, que se sedimenta nas formas do pensamento. Os conceitos filosóficos nos quais Platão e Aristóteles expõem o mundo exigiram, com sua pretensão de validade universal, as relações por eles fundamentadas como a verdadeira e efetiva realidade. Esses conceitos provêm, como diz Vico, da praça do mercado de Atenas" (Adorno e Horkheimer, 1985, p. 35). 
Demirovi, Alex. (2002), "Rekrutierung von Intellektuellen im Fordismus. Vergleichende Anmerkungen zu Horkheimers und Adornos Analyse der Kulturindustrie und Gramscis Analyse der Zivilgesellschaft". In: BRÜCHERT, Oliver \& RESCH, Christine (orgs.). Zwischen Herrschaft und Befreiung - kulturelle, politische und wissenschaftliche Strategien. Münster, Westfälisches Dampfboot, pp. 55-69.

Dubiel, Helmut. (1978), Wissenschaftsorganisation und politische Erfahrung - Studien zur frühen kritischen Theorie. Frankfurt am Main, Suhrkamp.

Genel, Katia. (2013), Autorité et emancipation: Horkheimer et la théorie critique. Paris, Payot. Habermas, Jürgen. (1986), “Nachwort”. In: Horkheimer, Max \& Adorno, Theodor W. Dialektik der Aufklärung - Philosophische Fragmente. Frankfurt am Main, Fischer, pp. 277-294.

Habermas, Jürgen. (1999), Teoria de la acción comunicativa - Vol. I: racionalidade de la acción y racionalización social. Madrid, Taurus.

Horkheimer, Max. ([1939] 1980), “Die Juden und Europa”. In: Horkheimer, Max (org.). Zeitschrift für Sozialforschung. Munique, DTV, vol. 8, pp. 115-137.

Horkheimer, Max. ([1943] 1985), “Zur Soziologie der Klassenverhältnisse”. Tradução do manuscrito original inglês feita por Hans Günther Zoll. In: Horkheimer, Max et al. Gesammelte Schriften. Frankfurt am Main, Fischer, vol. 12, pp. 75-104.

Horkheimer, Max. ([1930] 1987a), "Ein neuer Ideologiebegriff?”. In: Horkheimer, Max et al. Gesammelte Schriften. Frankfurt am Main, Fischer, vol. 2, pp. 271-294.

Horkheimer, Max. ([1942] 1987b), “Autoritärer Staat”. In: Horkheimer, Max et al. Gesammelte Schriften. Frankfurt am Main, Fischer, vol. 5, pp. 293-319.

Horkheimer, Max. ([1942] 1987c), "Vernunft und Selbsterhaltung”. In: Horkheimer, Max et al. Gesammelte Schriften. Frankfurt am Main, Fischer, vol. 5, pp. 320-350.

Horkheimer, Max. ([1947/1949] 1987d), "Autorität und Familie in der Gegenwart”. Tradução do manuscrito original inglês feita no âmbito do Instituto de Pesquisa Social. In: HorkHEIMER, Max et al. Gesammelte Schriften. Frankfurt am Main, Fischer, vol. 5, pp. 377-395.

Horkheimer, Max. ([1932] 1988a), "Bemerkungen über Wissenschaft und Krise”. In: HorKheimer, Max et al. Gesammelte Schriften. Frankfurt am Main, Fischer, vol. 3, pp. 40-47.

Horkheimer, Max. ([1937] 1988b), “Traditionelle und kritische Theorie”. In: Horkheimer, Max et al. Gesammelte Schriften. Frankfurt am Main, Fischer, vol. 4, pp. 162-216.

Horkheimer, Max. ([1937] 1988c), "Der neueste Angriff auf die Metaphysik". In: HorKHEIMER, Max et al. Gesammelte Schriften. Frankfurt am Main, Fischer, vol. 4, pp. 108-161.

Horkheimer, Max. ([1946] 2015), Eclipse da Razão. São Paulo, Editora Unesp.

Horkheimer, Max et al. ([1936] 1987), Studien über Autorität und Familie - Forschungsberichte aus dem Institut für Sozialforschung. Lüneburg, Dietrich zu Kampen.

KleIn, Stefan Fornos. (2012), A universidade e a sociologia sergundo Max Horkheimer: teoria, pesquisa e crítica. São Paulo, tese de doutorado, Faculdade de Filosofia, Letras e Ciências Humanas da Universidade de São Paulo. 
LENK, Kurt. (1986), “Ideologie und Ideologiekritik im Werk Max Horkheimers”. In: ScHmidT, Alfred \& Altwickler, Norbert (orgs.). Max Horkheimer heute: Werk und Wirkung. Frankfurt am Main, Fischer, pp. 244-258.

Marx, Karl. ([1967] 1983), O capital - Crítica da economia política. Vol. 1: O processo de produção do capital. Tradução de Regis Barbosa e Flávio Kothe. São Paulo, Abril Cultural.

Musse, Ricardo. (1997), Do socialismo científico à teoria crítica: modificações na autocompreensão do marxismo entre 1878 e 1937. São Paulo, tese de doutorado, Faculdade de Filosofia, Letras e Ciências Humanas da Universidade de São Paulo.

Neurath, Otto et al. (1929), Wissenschaftliche Weltauffassung - der Wiener Kreis. Wien, Artur Wolf.

Nobre, Marcos (2008), "Max Horkheimer: a teoria crítica entre o nazismo e o capitalismo tardio”. In: Nobre, Marcos (org.). Curso livre de teoria crítica. Campinas, Papirus, pp. 35-52.

Paulani, Leda. (2016), "Acumulação e rentismo: resgatando a teoria da renda de Marx para pensar o capitalismo contemporâneo". Revista de Economia Política, 36 (3): 514-535.

Pedroso, Gustavo. (2009), "Entre o capitalismo de Estado e o Behemoth: o Instituto de Pesquisa Social e o fenômeno do fascismo". Cadernos de Ética e Filosofia Política, 15 (2): 151-180.

Pollock, Friedrich. (1980), “State capitalism”. In: Horkheimer, Max (org.). Zeitschrift für Sozialforschung. 1ํㅡㄹ edição 1941. Munique, DTV, vol. 9, pp. 200-225.

Postone, Moishe. (1993), Time, labor and social domination: a reinterpretation of Marx'critical theory. Londres, Cambridge University Press.

Puzone, Vladimir. (2017), "Filosofia da história ou reprodução da vida dos indivíduos? A crítica de Max Horkheimer a Georg Lukács e a reformulação do marxismo”. Sociologia e Antropologia, 7 (1): 239-265.

Regatieri, Ricardo Pagliuso. (2015), Do capitalismo monopolista ao processo civilizatório: a crítica da dominação nos debates no instituto de Pesquisa Social na década de 1940 e na elaboração da Dialética do esclarecimento. São Paulo, tese de doutorado, Faculdade de Filosofia, Letras e Ciências Humanas da Universidade de São Paulo.

Rugitsky, Fernando. (2008), “Friedrich Pollock: limites e possibilidades”. In: Nobre, Marcos (org.). Curso livre de teoria crítica. Campinas, Papirus, pp. 53-72.

Tedeia, Gilberto. (2001), Materialismo em Horkheimer nos anos 30. São Paulo, dissertação de mestrado, Faculdade de Filosofia, Letras e Ciências Humanas da Universidade de São Paulo. 


\section{Resumo}

O fetichismo na ciência e a crise da razão

A crítica ao caráter fetichista da ciência contemporânea foi um elemento central das contribuições do Instituto de Pesquisas Sociais de Frankfurt. Com base nas obras de Horkheimer e Adorno, pretendemos ressaltar aspectos frequentemente negligenciados pela recepção da "teoria crítica", a saber: (a) a continuidade de fundo entre as reflexões feitas nos anos de 1930 e aquelas formuladas na Dialética do esclarecimento e em Eclipse da razão; (b) a importância, como elemento mediador entre esses dois períodos, das transformações pelas quais passava o capitalismo no entreguerras, tais como a integração do proletariado e a reconfiguração do uso da técnica; (c) o caráter histórico-materialista da interpretação feita pelos autores dos processos de subjetivação da razão e de inversão da ciência em magia.

Palavras-chave: Crítica da ciência; Fetichismo; Crítica do capitalismo.

\section{Abstract}

Fetishism in science and the crisis of reason

The critique of the fetishist character of contemporary science was central to the contributions of the Frankfurt Institute of Social Research. Based on the works of Horkheimer and Adorno, our aim is to emphasize aspects that are frequently neglected by the reception of "critical theory", namely: (a) the basic continuity between the reflections made in the 1930s and those formulated in Dialectic of enlightenment and Eclipse of reason; (b) the importance, as a mediating factor between these two periods, of the transformations through which capitalism has gone between the two great wars, such as the integration of working class and the reconfiguration of the use of technology; (c) the historical-materialistic character of the interpretation given by the authors to the processes of subjectivation of reason and of inversion of science in magic.

Keywords: Critique of science; Fetishism; Critique of capitalism.

Texto recebido em 6/4/2018 e aprovado em 13/5/2018.

DOI: 10.11606/0103-2070.ts.2018.145089.

FÁBIO DE MARIA é doutor em sociologia pela Faculdade de Filosofia, Letras e Ciências Humanas da Universidade de São Paulo (FFLCH-USP).E-mail: fabiodemaria@alumni.usp.br.

CARLOS HeNRIQUe PISSARDo é doutor em sociologia pela Faculdade de Filosofia, Letras e Ciências Humanas da Universidade de São Paulo (FFLCH-USP).E-mail: cpissardo@yahoo.com. 